\title{
Tıp Fakültesi, Sağlık Yüksekokulu ve Sağlık Meslek Yüksekokulu Öğrencilerinde Depresyonun Aile-Arkadaş iliş̧kisine ve Akademik Başarıya Etkisi
}

\author{
Dilek Kuzay (10)
}

Ahi Evran Üniversitesi Tıp Fakültesi, Fizyoloji, Kırşehir, Türkiye

Dilek Kuzay, Dr. Öğr. Üyesi

İletişim:

Dr. Öğr. Üyesi Dilek Kuzay

Ahi Evran Üniversitesi Tıp Fakültesi, Fizyoloji, Kırşehir, Türkiye

Tel: +903862803900

E-Posta:dilekkuzay@gmail.com

Gönderilme Tarihi : 04 Nisan 2018

Revizyon Tarihi : 12 Nisan 2018

Kabul Tarihi $\quad$ : 28 Nisan 2018
ÖZET

Amaç: Depresyon üniversite öğrencilerinde görülebilen önemli bir psikolojik rahatsızııtır. Bu çalışmanın amacı, tıp fakültesi, sağIık yüksekokulu ve sağlık meslek yüksekokulu öğrencilerinde depresyonun aile-arkadaş ilişkisine ve akademik başarıya etkisinin olup olmadığııı araştırmaktır.

Yöntem: Çalışmanın evrenini, bir üniversitenin tıp fakültesi (n:61), sağlık yüksekokulu (n:236) ve sağlık meslek yüksekokulunda (n:251) okuyan toplam 548 birinci sınıf ögrencilerinden oluşmaktadır. Çalısma tanımlayıcı olup, 01/05/2017-01/10/2017 tarihleri arasında gerçekleştirilmiştir. Veriler, literatür taraması ile oluşturulan anket formu ve Beck Depresyon ölçeği (BDÖ) aracılığı ile toplanmıştır.

Bulgular: Ders durumu kötü-çok kötü olan öğrencilerin BDÖ ortalamalarının, ders durumu orta ve iyi-çok iyi arasında olan öğrencilerin ortalamalarından daha yüksek olduğu saptanmıştır. (p<0.001). Arkadaşılık ilişki durumu Kötü-çok köttü olan öğrencilerin BDÖ ortalamalarının, arkadaşık ilişki durumu orta ve iyi-çok iyi arasında olan öğrencilerin ortalamalarından daha yüksek olduğu saptanmıştır ( $p<0.001)$. Ailevi ilişki durumu iyi-çok iyi olan öğrencilerin BDÖ ortalamalarının, ailevi ilişki durumu orta ve kötü-çok kötü arasında olan öğrencilerin ortalamalarından daha düşük olduğu saptanmıştır $(p<0.001)$.

Sonuç: Araştırma sonuçları öğrencilerde depresyonun akademik başarı, aile ve arkadaşılık ilişkilerini olumsuz etkilediğini göstermektedir. Toplumun önemli bir kısmını oluşturan üniversite öğrencilerinin okul başarılarını iyileştirmek ve aile-arkadaşık ilişkilerini güçlendirmek için danışmanlık hizmeti verilmesi gerekmektedir.

Anahtar sözcükler: Öğrenciler, akademik başarı, depresyon, ebeveyn, arkadaş

EFFECTS OF DEPRESSION ON FAMILY-FRIEND RELATIONSHIP AND ACADEMIC SUCCESS IN MEDICAL FACULTY, HEALTH HIGH SCHOOL AND VOCATIONAL HEALTH HIGH SCHOOL

\section{ABSTRACT}

Objectives: Depression is an important psychological disorder that can be seen in university students. The aim of this study is to investigate whether depression is influenced by family-friend relationship and academic achievement in medical faculty, health high school and vocational health high school.

Methods: The students' universe consists of a total of 548 first-year students studying at a university in the faculty of medicine ( $\mathrm{n}$ : $61)$, health college ( $n: 236)$ and health vocational college $(n: 251)$. The study is descriptive and was conducted between $01 / 05 / 2017-$ 01/10/2017. The data were collected through a questionnaire prepared by literature review and the Beck Depression Inventory (BDI).

Results: It was determined that students with a bad-to-poor condition had higher BDI averages than those with medium to goodto-good average $(P<0.001)$. It was found that the BDI averages of students with a bad-to-very bad friendship status were higher than those of middle to good-best students $(p<0.001)$. It was found that the BDI averages of the students with good-to-good family relations were lower than the average of the middle to poor-poor students $(p<0.001)$.

Conclusion: The results of the study show that depression negatively affects academic achievement, family and friendship relations in students. University students, who constitute a significant part of society, need counseling services to improve school achievements and strengthen family-friendship relationships.

Keywords: Students, academic success, depression, parents, friends 
niversite yılları gençlerin erişkinliğe geçiş yıllarıdır. Bu dönemde gençlerin ilişkilerinin çok hızı değişim gösterdiği bilinmektedir. Özellikle üniversitede okuma şansı elde edenler, üniversiteyi kazanma sevincinin yanı sıra; aileden ayrılma, yeni çevre ve arkadaş edinme, yalnız kalma korkusu, ekonomik güçlükler, yurt hayatına alışma, gelecekteki mesleği ve çalışma hayatı ile ilgili kaygı gibi birçok sorunla da yüz yüze kalır. Bu sosyal, kültürel ve ekonomik değişiklik gençleri ruhsal açıdan olumsuz etkileyebilir.

Üniversite gençleri arasında yapılan araştırmalarda, bu grubu tehdit eden en önemli psikolojik rahatsızlığın depresyon olduğu belirtilmektedir $(1,2)$. Depresyon genellikle iç sıkıntısı, daralma, huzursuzluk ile birliktedir. Depresyonun motivasyon üzerinde etkileri vardır. Önceleri severek yapılan işler bile artık keyif vermez olmuştur. Birey kendini hüzünlü ve yalnız hisseder. Kendisine ve çevresine ilgisi azalır. Olumlu duyguları azalır buna karşın olumsuz duyguları artar. Depresyon konsantrasyon ve hafıza üzerinede etkilidir. Dikkat toplanamadığı için kitap okumak, televizyon seyretmek gibi daha önceleri yapılan birçok eylem yapılamaz hale gelir. Tüm bu etkiler bireyin davranışlarını da değiştirir. Enerji azalmasından dolayı daha önce kolaylıkla yapılan işler gözde büyür, sosyal olarak içe çekilme ihtiyacı hissedilir (3).

Literatürdeki çalışmalara göre, öğrencilerde depresif belirtilerin ortaya çıkmasında bireysel, aile, arkadaş ve okul gibi çevresel etmenlerin yer aldığı gösterilmiştir (4). Huzurlu bir aile ortamında bulunmak, uygun anne-baba ve akran iletişimi kurmak gençlerin ruhsal gelişimini sağlamak için gerekli faktörlerdir. Akademik başarıya etkili faktörler psikolojik, sosyokültürel, sosyoekonomik ve aile yapısıdır. Öğrencilerin akademik alanda başarı göstermeleri, öz güveni yüksek bireyler olarak toplumda yer almaları ancak sağlıklı ruhsal gelişim ile mümkün olabilir.

Sağlık bölümünde okuyan öğrencilerde ders yoğunluğu nedeniyle depresyon sıklığı daha fazla görülmektedir. Bu çalışmanın amacı, tıp fakültesi, sağlık yüksekokulu ve sağlık meslek yüksekokulu öğrencilerinde depresyonun aile-arkadaş ilişkisine ve akademik başarıya etkisinin olup olmadığını araştırmaktır.

\section{Gereç ve yöntem}

\section{Çalışmanın tasarımı}

Çalışma tanımlayıcı tiptedir. 01/05/2017-01/10/2017 tarihleri arasında gerçekleştirilmiştir. Çalışmanın evreni, üniversitenin tıp fakültesi (n:61), sağlık yüksekokulu (n:236) ve sağlık meslek yüksekokulunda (n:251) okuyan toplam
548 birinci sınıf öğrencilerinden oluşturulmuştur, örneklem seçimine gidilmeyerek evrenin tümüne ulaşılmak amaçlanmıştır. Ancak, anket formunun uygulandığı günlerde devamsız olan ve çalışmaya katılmak istemeyenlerin olması nedeniyle 490 (\%89.42) kişi çalışmaya alınmıştır.

\section{Verilerin toplanması}

Araştırmanın verileri, araştırmacı tarafından literatür taraması ile oluşturulan soru formu ve BDÖ ile toplanmıştır (5). Soru formu, katılımcıların sosyodemografik bilgileri ve okul başarısı, aile ve arkadaş ilişkileri ile ilgili bilgileri içermektedir. Toplam 10 sorudan oluşmaktadır.

BDÖ, toplam 21 sorudan oluşan ve her yanıttan elde edilen 0-3 arasındaki puanların toplanması ile değerlendirilen, depresyon derecelendirme ölçeğidir. Toplam puan aralıkları doğrultusunda ölçek, 1-10 arası normal, 11-16 arası orta derecede duygu durumu bozukluğu, 17-20 arası klinik depresyon; 21-30 arası orta düzeyde depresyon; 31-40 arası ciddi düzeyde depresyon; 41-63 arası ağır depresyon biçiminde değerlendirilmektedir. Ölçeğin Türkçe geçerlilik ve güvenilirlik çalışması Hisli tarafından yapılmıştır (6).

\section{Verilerin değerlendirilmesi}

Veriler SPSS.20.00 paket program kullanarak değerlendirilmiş, tanımlayıcı verilerde yüzde, sayı ve ortalama değerler verilerek sunulmuştur. Değişkenlerin normal dağılıma uygunluğu Kolmogorov-Smirnov testi ile incelenmiştir $(p<0.001)$. İstatistiki analizlerde Mann-Whitney $U$ testi ve Kruskal-Wallis testi kullanılmıştır. Araştırmanın uygulamasına başlamadan önce üniversitelerin Tıp Fakültesi, Sağlık Yüksekokulu, Sağlık Meslek Yüksekokulu Dekanlıklarından yazılı izin ve araştırmaya katılan öğrencilerden yazııı onam alınmıştır. Araştırma öncesi İnsan Üzerinde Yapılan Klinik Dışı Araştırmalar Etik Kurulu'ndan etik onay (karar sayısı: 2016-11/01) alınmıştır.

\section{Bulgular}

Öğrencilerin $277(\% 56,5)$ 'si 20 yaş ve altı olup, 318 $(\% 64,9)^{\prime} i$ kız öğrencidir. Öğrencilerin \%52,1'i Sağlık yüksekokulunda okumaktadır. \%46,5'i ders başarısı durumunun, \%75,3'ünün arkadaş ilişkisi durumun, \%85,3'ü aile ilişki durumunun iyi veya çok iyi olduğunu belirtmişlerdir. Çalışmaya katılan öğrencilerin sosyo-demografik özellikleri Tablo 1'de görülmektedir.

Çalışmaya katılanların Beck depresyon puan ortancası 11.00 (min:0 - maks:66) olarak hesaplanmıştır. Katılımcıların \%46,9'unun beck depresyon düzeyi normal, $\% 23,7$ 'sı orta, ciddi veya çok ciddi depresyonda olduğu tespit edilmiştir (Tablo 2). 
Tablo 1. Öğrencilerin bazı sosyo-demografik özellikleri

\begin{tabular}{lcc} 
Değişkenler & Sayı (n) & Yüzde (\%) \\
\hline Yaş & & \\
20 yaş altı & 277 & 56,5 \\
21 yaş ve üzeri & 213 & 43,5 \\
Cinsiyet & & \\
Kız & 318 & 64,9 \\
Erkek & 172 & 35,1 \\
Bölüm & & \\
Tıp fakültesi & 55 & 11,2 \\
Sağlık Yüksekokulu & 255 & 52,1 \\
Sağlık meslek okulu & 180 & 36,7 \\
Ders durumu & & \\
Çok kötü-Kötü & 41 & 8,4 \\
Orta & 221 & 45,1 \\
Çok iyi- iyi & 228 & 46,5 \\
Arkadaş ilişkisi durumu & & \\
Çok kötü-Kötü & 26 & 5,3 \\
Orta & 95 & 19,4 \\
Çok iyi- iyi & 369 & 75,3 \\
Aile ilişkisi durumu & & \\
Çok kötü-Kötü & 20 & 4,1 \\
Orta & 52 & 85,3 \\
Çok iyi- iyi & 418 & \\
& &
\end{tabular}

Tablo 2. Öğrencilerin Beck depresyon düzeyi puanlarının dağılımı

\begin{tabular}{lcc} 
Beck depresyon düzeyi & Sayı & Yüzde \\
\hline Normal & 230 & 46,9 \\
Hafif ruhsal sıkıntı & 99 & 20,2 \\
Sınırda Klinik depresyon & 45 & 9,2 \\
Orta depresyon & 64 & 13,1 \\
Ciddi depresyon & 42 & 8,6 \\
Çok ciddi depresyon & 10 & 2,0
\end{tabular}

Yaş, cinsiyet ve okuduğu bölüm ile BDÖ puanları arasında istatistiksel olarak anlamlı bir fark saptanmamıştır ( $p>0.05$ ). Ders durumu ile BDÖ puanları arasında anlamlı bir fark olduğu tespit edilmiştir $(p<0.001)$. Oluşan bu farkın hangi gruplar arasında olduğunu tespit etmek için $p$ değerleri üzerine Bonferroni düzeltmeli Mann-Whitney $U$ testi yapılmıştır. Bu farkın ders durumu kötü-çok kötü olan ile iyi-çok iyi olan gruplardan kaynaklandığı tespit edilmiştir. Ders durumu kötü-çok kötü olan öğrencilerin BDÖ puanları, ders durumu iyi-çok iyi olan öğrencilerin puanlarına göre daha yüksek olduğu saptanmıştır.

Arkadaşlık ilişki durumu ile BDÖ puanları arasında anlamlı bir fark olduğu saptanmıştır ( $p<0.001$ ). Oluşan bu farkın hangi gruplar arasından olduğunu tespit etmek için $p$ değerleri üzerine Bonferroni düzeltmeli Mann-Whitney U testi yapılmıştır. Bu fark arkadaşlık ilişki durumu kötü-çok
Tablo 3. Öğrencilerin bazı sosyo-demografik özellikleri ile BDÖ puanlarının karşılaştırıması

\begin{tabular}{|c|c|c|c|}
\hline Değişkenler & $n$ & $\begin{array}{l}\text { Beck puan ortancası } \\
\text { (min-maks) }\end{array}$ & $p$ \\
\hline \multicolumn{4}{|l|}{ Yaş } \\
\hline 20 yaş altı & 277 & $11.00(0-59)$ & \multirow{2}{*}{$P=0.960$ * } \\
\hline 20 yaş ve üzeri & 213 & $11.00(0-66)$ & \\
\hline \multicolumn{4}{|l|}{ Cinsiyet } \\
\hline Kadın & 318 & $11.50(0-59)$ & \multirow{2}{*}{$p>0.05^{\star}$} \\
\hline Erkek & 172 & $11.00(0-66)$ & \\
\hline \multicolumn{4}{|l|}{ Bölüm } \\
\hline Tıp fakültesi & 55 & $13.00(0-59)$ & \multirow{3}{*}{$p>0.05^{\star *}$} \\
\hline Sağlık Yüksekokulu & 255 & $11.00(0-44)$ & \\
\hline Sağlık meslek okulu & 180 & $12.00(0-44)$ & \\
\hline \multicolumn{4}{|l|}{ Ders durumu } \\
\hline Çok kötü-Kötü & 41 & $20.00(0-66)$ & \multirow{3}{*}{$\mathrm{p}<0.001^{* *}$} \\
\hline Fena değil & 221 & $12.00(0-41)$ & \\
\hline Çok iyi- iyi & 228 & $10.00(0-66)$ & \\
\hline \multicolumn{4}{|c|}{ Arkadaş ilişkisi durumu } \\
\hline Çok kötü-Kötü & 26 & $22.50(1-66)$ & \multirow{3}{*}{$p<0.001^{* *}$} \\
\hline Fena değil & 95 & $15.00(0-44)$ & \\
\hline Çok iyi- iyi & 369 & $10.00(0-66)$ & \\
\hline \multicolumn{4}{|l|}{ Aile ilişkisi durumu } \\
\hline Çok kötü-Kötü & 20 & $14.50(1-66)$ & \multirow{3}{*}{$p<0.001^{* *}$} \\
\hline Fena değil & 52 & $19.5(0-59)$ & \\
\hline Çok iyi- iyi & 418 & $10.00(0-66)$ & \\
\hline
\end{tabular}

kötü olan ile iyi-çok iyi ve orta düzeyde olan gruplar arasından kaynaklandığı tespit edilmiştir. Arkadaşık ilişki durumu kötü-çok kötü olan öğrencilerin BDÖ puanlarının, arkadaşlık ilişki durumu orta ve iyi-çok iyi olan öğrencilerin ortalamalarından daha yüksek olduğu saptanmıştır.

Ailevi ilişki durumu BDÖ puanları arasında anlamlı bir fark olduğu saptanmıştır $(p<0.001)$. Oluşan bu farkın hangi grupların arasından olduğunu tespit etmek için $p$ değerleri üzerine Bonferroni düzeltmeli Mann-Whitney $U$ testi yapılmıştır. Bu fark ailevi ilişki durumu kötü-çok kötü ile iyi-çok iyi ve orta düzeyde olan gruplardan kaynaklandığı tespit edilmiştir. Ailevi ilişki durumu iyi-çok iyi olan öğrencilerin BDÖ puanlarının, ailevi ilişki durumu orta ve kötü-çok kötü $(23,50 \pm 3,21)$ arasında olan öğrencilerin ortalamalarından daha düşük olduğu saptanmıştır (Her bir değişken için ortanca ve min-maks değerler Tablo 3'te verilmiştir).

Bölümler arasında akademik başarısı, aile ilişkileri ve arkadaşlık ilişkileri kötü ve çok kötü olarak belirtenlerin 
depresyon ortalama puanları arasında istatistiksel olarak anlamlı bir fark saptanmamıştır ( $p>0.05)$. Akademik başarısı, aile ilişkileri ve arkadaşlık ilişkileri kötü ve çok kötü olarak belirten sağlık meslek yüksekokulu öğrencilerinin BDÖ puan ortalamaları diğer bölümlerde okuyanlara göre daha yüksek olduğu tespit edilmiştir (Tablo 4).

Tablo 4. Kötü düzey seçen öğrencilerin özellikleri ile BDÖ puanlarının karşılaştırıması

\begin{tabular}{lcccc} 
Bölümler & $\boldsymbol{n}$ & $\%$ & BDÖ & $\boldsymbol{p}$ \\
\hline $\begin{array}{l}\text { Akademik başarısı en kötü-Kötü } \\
\text { olanların BDÖ puan ortancaları }\end{array}$ & & & & \\
Tıp Fakültesi & 12 & 29,3 & $23.50(0-59)$ & \\
Sağlık Yüksekokulu & 14 & 34,1 & $14.50(3-44)$ & $0,802^{*}$ \\
Sağlık Meslek Yüksekokulu & 15 & 36,6 & $24.00(1-66)$ & \\
\hline Arkadaşlık ilişkisi en kötü-Kötü & & & & \\
olanların BDŐ puan ortancaları & 7 & 26,9 & $21.00(7-59)$ & \\
Tıp Fakültesi & 8 & 30,8 & $19.50(11-32)$ & $0,665^{*}$ \\
Sağlık Yüksekokulu & 11 & 42,3 & $28.00(1-66)$ & \\
Sağlık Meslek Yüksekokulu & & & & \\
\hline Aile ilişkisi en kötü-Kötü olanların & & & & \\
BDÖ puan ortancaları & 1 & 5,0 & 15.00 & \\
Tıp Fakültesi & 6 & 30,0 & $24.50(11-34)$ & $0,630^{*}$ \\
Sağlık Yüksekokulu & 13 & 65.0 & $25.00(1-66)$ & \\
Sağlık Meslek Yüksekokulu & & &
\end{tabular}

\section{Tartışma}

Depresyon üniversite öğrencileri arasında yaygın bir problemdir. Öğrencilerin çevrelerindeki kişilerle ilişkilerini ve akademik performansını kötü etkiler. Çalışmamız sonuçlarına göre kız ve erkek öğrencilerin BDÖ ortalamalarında bir fark bulunamamıştır. Deb. ve ark. üniversite öğrencilerinde yaptığı araştırmada kız ve erkek öğrencilerin depresyona yatkınlıkları arasında bir fark saptamamıştır (7). Bazı çalışmalar kız öğrencilerin erkeklere göre depresyona daha yatkın olduğunu bildirirken $(8,9)$, bazı çalışmalarda erkek öğrencilerin kızlara göre akran mağduriyetine daha çok maruz kaldığı için depresyona daha yatkın olduklarını bildirmişlerdir (10).

Bölümlere göre BDÖ puanı incelendiğinde, tıp fakültesi ve sağlık meslek yüksekokulu öğrencilerinde BDÖ puanının sağlık yüksekokulu öğrencilerine göre daha yüksek olduğu bulunmuştur. Bunun nedeninin tıp fakültesi öğrencilerinin derslerinin zor olması, sağlık meslek yüksekokulu öğrencilerinde ise okulun iki yıllık olması ve daha birinci sınıfta öğrencilerin iş bulma kaygısı yaşamasından kaynaklandığı düşünülmektedir.
Çalışmamız sonuçlarına göre ders durumu kötü ve çok kötü olan öğrencilerin BDÖ ortalamalarının, ders durumu orta ve iyi-çok iyi arasında olan öğrencilerin ortalamalarından daha yüksek olduğu saptanmıştır. Liu ve arkadaşlarının çalışmaları da bizim sonuçlarımızı desteklemektedir. Okul başarısı kötü olan öğrencilerde depresyon görülme oranı artmıştır (10). Eğitim bilimleri, yabancı diller ve güzel sanatlar fakültesi öğrencilerinde yapılan bir çalışmada öğrencilerin başarılarını algılamalarına göre, kendilerini başarısız olarak algılayanların depresyon düzeyinin başarılı olarak algılayanlara göre daha fazla olduğu saptanmıştır (11). Aydın (1988) araştırmasında, başarısız öğlencilerin depresif belirtilerinin, başarılı öğrencilere göre daha fazla olduğunu ve depresif bireylerde başarısızlığın benlik kavramını olumsuz yönde etkilediğini vurgulamıştır (12). Bir başka araştırmada depresyonun üniversite öğrencilerinde ders çalışma tutum ve alışkanlıklarını anlamlı olarak etkilediğini bulmuştur (13). Bu yüzden üniversite öğrencilerinde gelecekteki kariyer planları ve akademik stresleri ile başa çıkabilmelerine yönelik destek sağlanmalıdır.

Arkadaşlık ilişki durumu kötü ve çok kötü olan öğrencilerin BDÖ ortalamalarının, arkadaşlık ilişki durumu orta ve iyiçok iyi arasında olan öğrencilerin ortalamalarından daha yüksek olduğu saptanmıştır. Liu ve ark. nın yaptığı çalışma sonuçlarına göre akran mağduriyetine uğrayan öğrencilerin depresyon görülme oranı artmıştır (10). Bir başka çalışma depresif öğrencilerin akran bağlılığının depresif olmayanlara göre daha az olduğunu ileri sürmektedir (4).

Çalışmamız sonuçları ailevi ilişki durumu iyi-çok iyi olan öğrencilerin BDÖ ortalamalarının, ailevi ilişki durumu orta ve kötü-çok kötü arasında olan öğrencilerin ortalamalarından daha düşük olduğunu göstermiştir. Literatürdeki çalışmalarda bizim bulgumuzu destekler niteliktedir. Mutlu aile ortamı gençlerin ruhsal gelişimini olumlu etkilemektedir. Anne ve baba ile olumlu ilişkiler gençlere zihinsel barış, duygusal destek ve kendini güvende hissetme duygusu sağlamaktadır $(7,14,15)$. Lim ve arkadaşları lise yıllarındaki depresif öğrencilerde aile çatışmasının depresif olmayanlara göre daha fazla olduğunu açıklamıştır (4). Ebeveyn desteği ve anne ile güzel ilişkiler içinde geçirilen zamanın ergenler arasında depresif belirtileri azalttığını ve hatalı davranışları önlediğini gösteren çalışmalarda mevcuttur $(16,17)$. Zhai ve ark. iyi bir aile ortamı kurmanın öğrencilerde depresyonun önlenmesi açısından önemli olduğunu öne sürmektedir (18). Bu nedenle depresif ergenlerin aile ve akran ilişkileri değerlendirilmeli ve bu ilişkilerini güçlendirici stratejiler geliştirilmelidir. 


\section{Kısıtlılık}

Örnekler sadece bir üniversitenin sağlık ile ilgili bölümlerinde yapılmıştır. Tüm sağlık bölümlerini temsil etmemektedir. Çalışma verileri soru formu ile toplandığından derinlemesine analiz yapmak için niteliksel çalışmaların yapılması gerekmektedir.

\section{Sonuç}

BDÖ puan ortalamaları ile arkadaşlık ilişki durumu, ailevi ilişki durumu ve akademik başarı arasında bir ilişki olduğu saptanmıştır. Öğrencilerde depresyon okul başarısını

\section{Kaynaklar}

1. Bumbery $W$. Validation of the $B D I$ in a university population using psychiatric estimate as the criterion. J Consult Clin Psychol 1978;46:150-5. [CrossRef]

2. Sherer M. Depression and suicidal ideation in college students. Psychol Rep 1985;57:1061-2. [CrossRef]

3. Antkiewicz-Michaluk L, Wạsik A, Możdżeń E, Romańska, Michaluk J. Antidepressant-like Effect of Tetrahydroisoquinoline Amines in the Animal Model of Depressive Disorder Induced by Repeated Administration of a Low Dose of Reserpine: Behavioral and Neurochemical Studies in the Rat. Neurotox Res 2014;26:85-98. [CrossRef]

4. Lim HJ, Chung SS, Joung KH. Factors of Depressive Symptoms Among Elementary, Middle, and High School Students. Arch Psychiatr Nurs 2016;30:302-8. [CrossRef]

5. Beck AT, Ward CH, Mendelson M, Mock J, Erbaugh J. An inventory far measuring depression. Arch Gen Psychiatry 1961;4:561-71. [CrossRef]

6. Hisli N. Beck Depresyon Envanterinin üniversite öğrencileri için geçerliği, güvenirliği. Psikoloji Derg 1989;7:3-13. Erişim: https:// toad.halileksi.net/sites/default/files/pdf/beck-depresyon-envanteritoad.pdf

7. Deb S, Banu PR, Thomas S, Vardhan RV, Rao PT, Khawaja N. Depression among Indian university students and its association with perceived university academic environment, living arrangements and personal issues. Asian J Psychiatry 2016;23:108-17. [CrossRef]

8. Van de Velde S, Bracke P, Levecque K. Gender differences in depression in 23 European countries. Cross-national variation in the gender gap in depression. Soc Sci Med 2010;71:305-13. [CrossRef]

9. Khawaja NG, Duncanson K. Using the university student depression inventory to investigate the effect of demographic variables on students' depression. Aust J Guid Couns 2008;18:195-209. [CrossRef] olumsuz etkilemektedir. Bu konuda öğrencilerin motivasyonunu artırmak için üniversitelerde danışmanlık hizmetlerinin verilmesi ve öğrencilerin bu hizmeti etkin olarak kullanması faydalı olacaktır.

Araştırma sonuçları öğrencilerde depresyonun aile ve arkadaşlık ilişkilerini olumsuz etkilediğini göstermektedir. Bu sonuçlar, üniversite öğrencilerinin duygusal sorunları konusunda profesyonel düzeyde rehberlik ve psikolojik danışma hizmetlerinin verilmesi gereğinin önemini vurgulaması açısından önemlidir.

10. Liu J, Bullock A, Coplan RJ, Chen X, Li D, Zhou Y. Developmental cascade models linking peer victimization, depression, and academic achievement in Chinese children. $\mathrm{Br} J$ Dev Psychol 2018;36:47-63. [CrossRef]

11. Bozkurt N. Bir Grup Üniversite Öğrencisinin Depresyon ve Kaygı Düzeyleri ile Çeşitli Değişkenler Arasındaki İlişkiler. Eğitim ve Bilim 2004;29:32-9. Erişim: http://egitimvebilim.ted.org.tr/index.php/EB/ article/view/5095/1179

12. Aydın G. Üniversite öğrencilerinde depresyon, açıklama biçimi ve akademik başarı ilişkisi. Türk Psikoloji Derg 1988;6:6-13.

13. Aydın B. Üniversite Öğrencilerinin Bir Kesiminde Çalışma Alışkanlıkları ve Tutumları ile Depresyon Seviyelerinin İncelenmesi. MÜ Atatürk Eğ Fak Eğ Bil Derg 1989;1:8-15. Erişim: https://dergipark. org.tr/download/article-file/2093

14. Coombs RH. Marital status and personal well-being: a literature review. Fam Relat 1991;40:97-102. [CrossRef]

15. Kessler RC, Essex M. Marital status and depression: the importance of coping resources. Soc Forces 1982;61:484-507. [CrossRef]

16. Kwak YS, Lee Cl, Hong SC, Song YJ, Kim IC, Moon, et al. Depressive symptoms in elementary school children in Jeju Island, Korea: Prevalence and correlates. Eur Child Adolesc Psychiatry 2008;17:34351. [CrossRef]

17. Ritakallio $M$, Luukkaala $T$, Marttunen $M$, Pelkonen $M$, Kaltiala-Heino R. Comorbidity between depression and antisocial behaviour in middle adolescence: The role of perceived social support. Nordic J Psychiatry 2010;64:164-71. [CrossRef]

18. Zhai H, Chen L, Yang Y, Sun H, Pan H, He J, et al. Family and College Environmental Exposures Mediate the Relationship between Parental Education and Depression among College Students. Plos ONE 2016;11:e0151759. [CrossRef] 